\title{
СЕКЬЮРИТИЗАЦИЯ БАНКОВСКИХ АКТИВОВ: ИННОВАЦИОННЫЕ ФИНАНСОВЫЕ ИНСТРУМЕНТЫ НА РЫНКЕ ИПОТЕКИ
}

\author{
(c) 2018 Янов Виталий Валерьевич \\ доктор экономических наук, профессор, заведующий кафедрой «Финансы и кредит» \\ Поволжский государственный университет сервиса \\ 445677, Самарская обл., г. Тольятти, ул. Гагарина, д. 4 \\ E-mail:kaf_fin@tolgas.ru
}

(c) 2018 Иноземцева Елена Юрьевна

кандидат экономических наук, доцент кафедры «Финансы и кредит»

Поволжский государственный университет сервиса

445677, Самарская обл., г. Тольятти, ул. Гагарина, д. 4

E-mail: inozemceva_e@mail.ru

Приоритеты социально-экономического развития и задачи обеспечения жильем населения РФ потребовало новых научных подходов. Изменение рыночной конъектуры привели к трансформации системы финансирования и кредитования объектов жилищного строительства, что оказало воздействие на механизм приобретение жилья гражданами страны.

Ключевые слова: секьюритизация, ипотечные бумаги, балансовая и внебалансовая секьюритизация, ипотечный кредит.

В деятельности государства одним из приоритетных направлений его функционирования является формирование соответствующих условий, позволяющих повысить доступность приобретения жилья для граждан. Допустимость на российском рынке жилой недвижимости является сложным многогранным индикатором, который отражает не только ход рыночных приобретений в жилищной сфере, её социальную направленность, но и связан с социально-экономическими процессами в обществе. Возможности улучшения жилищных условий осуществляется под воздействием процесса, в котором тесно переплетаются демографические, социально-экономические показатели уровня жизни населения, бюджетно-нормативная и кредитно-финансовая системы, ценовая и тарифная политики в сфере строительства жилой недвижимости и жилищно-коммунального обслуживания. Приобретение собственного жилья первоочередная потребность каждой семьи, без удовлетворения которой, теряются социальные приоритеты общества. В связи с этим, практическая реализация прав населения на жилую недвижимость является важной задачей социально-экономического развития. В зависимости от подходов её решения зависят объемы и темпы строительства жилья, уровень благосостояния населения, политические оценки и мотивация поведения.
Для эффективного жилищного строительства в России необходимо обобщить и использовать опыт ипотечного кредитования экономически развитых европейских стран в целях возможного его применения для повышения доступности жилья. Один из способов расширения масштабов доступности жилья, получившего развитие в развитых странах называется секьюритизацией, под которой понимается трансформация активов в рыночные ценные бумаги с последующей продажей их инвесторам. Секьюритизация, превращая недвижимость в долговые обязательства в форме ценных бумаг, способствует повышению их оборачиваемости, направляет в инфраструктуру фондового рынка. Секьюритизация это трансформация активов в более ликвидные, лучшего качества, востребованные рынком. Особо привлекательными для инвесторов являются активы, представленные ломбардными ценными бумагами, в число которых входят облигации с ипотечным покрытием «ВТБ 24» нескольких серий, облигации Банка Москвы. Задача секьюритизации сводится к выпуску высокорейтинговых бумаг с низкой доходностью. Типовая схема рефинансирования ипотечных кредитов представлена на рисунке 1 :

1,2,3. ипотечные банки группируют в управляющей компании ипотечные закладные типов A, Б, B;

4. управляющая компания передает паке- 
6

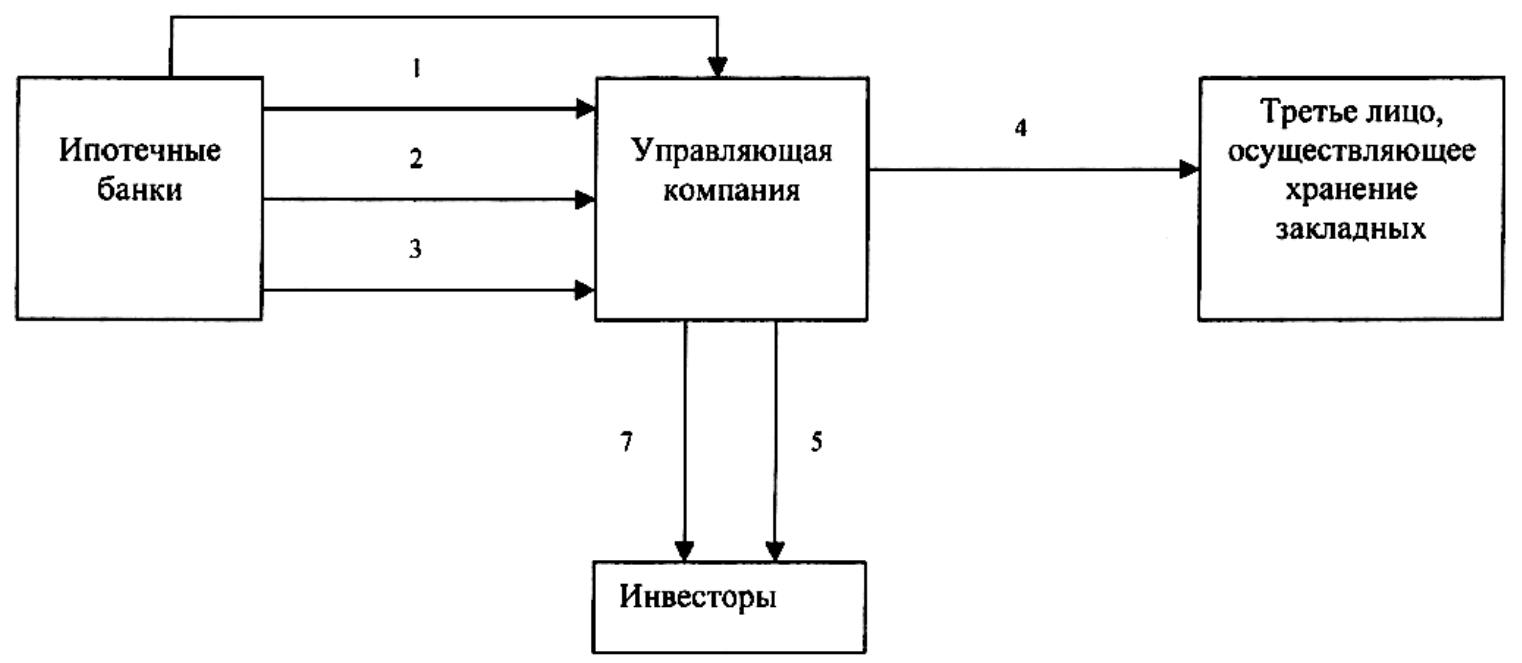

Puc. 1. Модель рефинансирование ипотечных кредитов путем обращения их в ценные бумаги.

ты закладных третьему лицу, осуществляющему хранение закладных;

5. управляющая компания выпускает на основе закладных ценные бумаги и продает их инвесторам;

6. ипотечный банк перечисляет в управляющую компанию платежи по ипотечным кредитам, полученные от заемщиков;

7. управляющая компания осуществляет выплату инвесторам доходов по ценным бумагам.

Процесс секьюритизации является сложной и многоэтапной процедурой, инициатором которой выступает коммерческий банк, предоставивший кредит на покупку недвижимости. Рефинансирование ипотечного актива позволит ему улучшить показатели ликвидности за счет продажи долгосрочных кредитов.

На первом этапе секьюритизации создается специальная управляющая компания, которая мобилизует ипотечные закладные и выпускает на их основе ценные бумаги. Это и позволяет отделить ипотечные активы от баланса банка-инициатора, а, следовательно, и всех причитающихся платежей по кредитам. Такая структура сделки дает инвесторам гарантию получения средств в случае финансовой несостоятельности банка-инициатора. Банки - держатели ипотечных закладных открывают для управляющей компании специальные накопительные счета, на которых сосредотачиваются все платежи, поступающие в уплату кредитов и процентов по ним. Далее средства распределяются среди инвесторов в качестве доходов по купленными ими ценным бумагам.
Предположим, что несколько ипотечных банков выдало различное количество долгосрочных займов типа А, Б и В.Данные займы различают как по сроку и величине ставки процента. Соответственно банки имеют ипотечные закладные типа А, Б и В. Закладные передаются в управляющую компанию, которая принимает на себя обязательство по передаче банкам через определенный, достаточно короткий срок соответствующую сумму денег. Контроль сроков является важным моментом, так как у банка всегда должно быть достаточно средств для своевременного исполнения своих обязательств. Все ипотечные закладные переходят на баланс управляющей компании, которая на следующем этапе секьюритизации объединяет закладные одного типа, полученные от разных банков, в пакеты типа А, Б и В. Таким образом, обязательства, имеющие разные характеристики, объединяются в одно, где в качестве должника выступают заемщики по ипотечным кредитам (т.е. несколько лиц), несущие долевую ответственность в рамках своего обязательства по договору займа. Прежде чем, ипотечные закладные будут объединены в единый пул они проверяются независимым оценщиком с целью определения степени их надежности. Подобное объединение не затрагивает положение должников, так как характер их ответственности и размер займа остались неизменны. Банки-инициаторы продолжают принимать платежи в счет погашения кредита от должников, но зачисляют их специальный накопительный счет управляющей компании.

На следующем этапе управляющая компа- 
ния передает сформированные пакеты третьему лицу на хранение и выпускает на их основе ценные бумаги, доходы от продажи которых являются средствами рефинансирования. Третье лицо служит хранителем закладных и гарантом выполнения компанией своих обязательств перед покупателями ее ценных бумаг.

В англо-американской системе права сделки секьюритизации сопровождаются созданием траст - агент или доверительного собственника, который и гарантирует передачу долговых обязательств собственникам ценных бумаг и осуществляет выплату доходов инвесторам-держателям ценных бумаг.

В зависимости от формы (модели осуществления) выделяют: балансовую и внебалансовую (традиционную) секьюритизацию активов. Под балансовой секьюритизацией активов понимают выпуск ипотечных ценных бумаг, обеспеченных залогом прав требования. При данной форме все выпущенные ценные бумаги остаются на балансе эмитента. Данная модель секьюритизации получила развитие в Германии и странах Скандинавии. Типичным примером такой секьюритизации является немецкая схема Pfandbrief, в которой активы находятся на определенных статьях баланса и не могут использоваться в других целях. Одновременно банк выпускает облигации, гарантирующие первоочередное право требования держателя на вышеуказанные активы в случае банкротства эмитента.

Рисунок 2.1:

1. Выдача ипотечных ссуд заемщикам.

2. Выпуск и размещение ценных бумаг, обеспеченных будущими поступлениями по ссудам.

3. Получение денежных средств от инвесторов в оплату ценных бумаг.

4. Выполнение заемщиками обязательств по уплате процентов и части основной долга по кредиту.

5. Выплата доходов инвесторам в виде купона и частичное погашение номинала ценных бумаг.

6. Переход прав требований по ссудам к инвесторам в случае банкротства банка (секьюритизируемые активы выделяются из конкурсной массы).

Стоит отметить, что ипотечные кредиты, оставшиеся на балансе банка, переводятся в отдельный реестр учета ипотечного обеспечения и находятся под постоянным контролем независимого поверенного, назначаемого либо самим банком или органом, контролирующем его деятельность.

Внебалансовую (традиционной) секьюритизацию определяют как инновационный способ финансирования, позволяющий рефинансировать ипотечные кредиты, имеющиеся у банка (оригинатора), за счет передачи прав требований специально созданной инвестиционной компании (special - purpose vehicle, SPV), финансирующей приобретение активов при помощи выпуска долговых инструментов (рис. 2.3). Средства, получаемые от размещения ценных бумаг SPV передает оригинатору в счет оплаты прав требования. В дальнейшем выплата основного долга и процентов держателям ценных бумаг осуществляется за счет поступлений от кредитов, права требования, но которым переданы SPV. Модель внебалансовой секьюритизация применяется в таких странах как США, Австралия, Великобритания, а также в ряде стран Азии и Латинской Америки. Внебалансовая секьюритизация включает в себя следующие этапы:

1. банк - первичный кредитор выдает ипотечные кредиты заемщикам, получая тем самым право на платежи по кредиту и право залогодержателя;

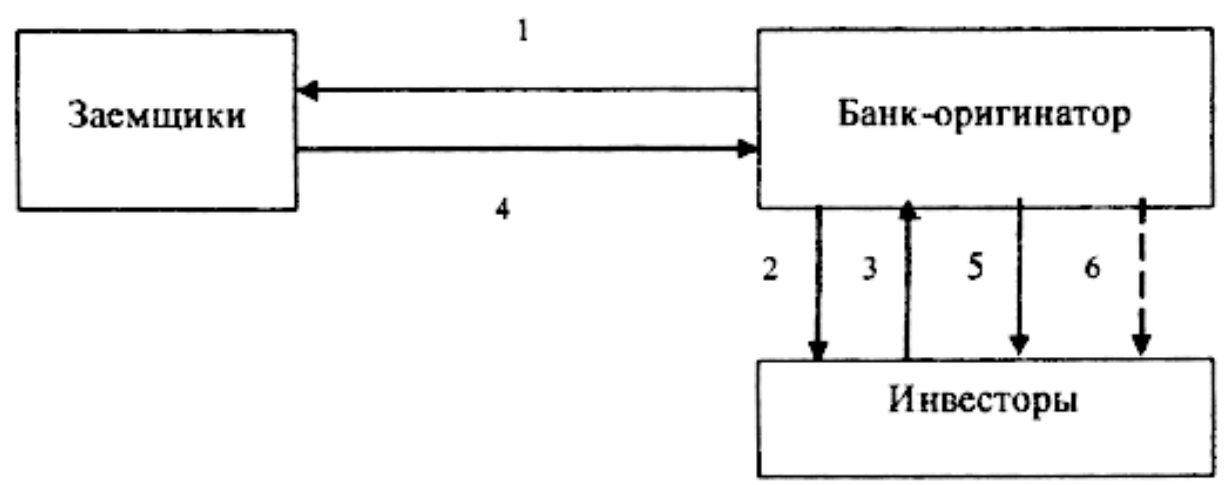

Рис. 2.1. Балансовая секьюритизация банковских активов 
2. специально созданная организация, SPV, приобретает у банка - кредитора права требования по кредитам, а так же права залогодержателя. При этом банк продолжает обслуживание кредитов, а так же осуществляет процедуру обращения взыскания на залоговое обеспечение, в случае если должник по ипотечному кредиту, входящему в пул, перестает выполнять свои обязательства;

3. на основе пула однотипных кредитов, SPV, выпускает ценные бумаги и продает их инвесторам.

Первый опыт создания SPV принадлежит США, а именно таким организациям как FNMA («Фэнни Мэй»), GNMA («Джинни Мэй») и FHLMC («Фредди Мак»), которые пользуются поддержкой государства.

Рисунок 2.2:

1. Предоставление кредитов заемщикам.

2. Создание пула ипотечных кредитов и их передача специально созданной проектной компании (SPV).

3. Предоставление кредитной поддержки (крупные банки, специализированные страховые компании).

4. Предоставление консультаций при структурировании сделки и присвоение кредитного рейтинга выпущенным SPV ценным бумагам.
5. Выпуск и продажа ценных бумаг инвесторам.

6. Поступление средств в оплату купленных инвесторами ценных бумаг.

7. Оплата переданного SPV пула ссуд.

8. Выполнение заемщиками обязательств в части уплаты процентов по кредиту и части основной суммы.

9. Перечисление SPV всех потоков по кредитам, вошедших в пул.

10. Выполнение обязательств перед инвесторами в виде выплат купонных платежей и части номинала ценных бумаг.

11. Оплата вознаграждения за кредитную поддержку.

12. Выплаты рейтинговому агентству.

13. Перечисление остаточной прибыли банку-оригинатору.

На основе особенностей рассмотренных моделей секьюритизации можно отметить следующие отличия (табл. 1).

Традиционной модели секьюритизации присущ и ряд недостатков: высокие затраты на обеспечение подлинной продажи, особенности в налоговом учете, раскрытие конфиденциальной информации о заемщике и т.д. Применение получивших широкое распространение в мировой практике схем секьюритизации банковских активов в России затруднено целым рядом обстоя-

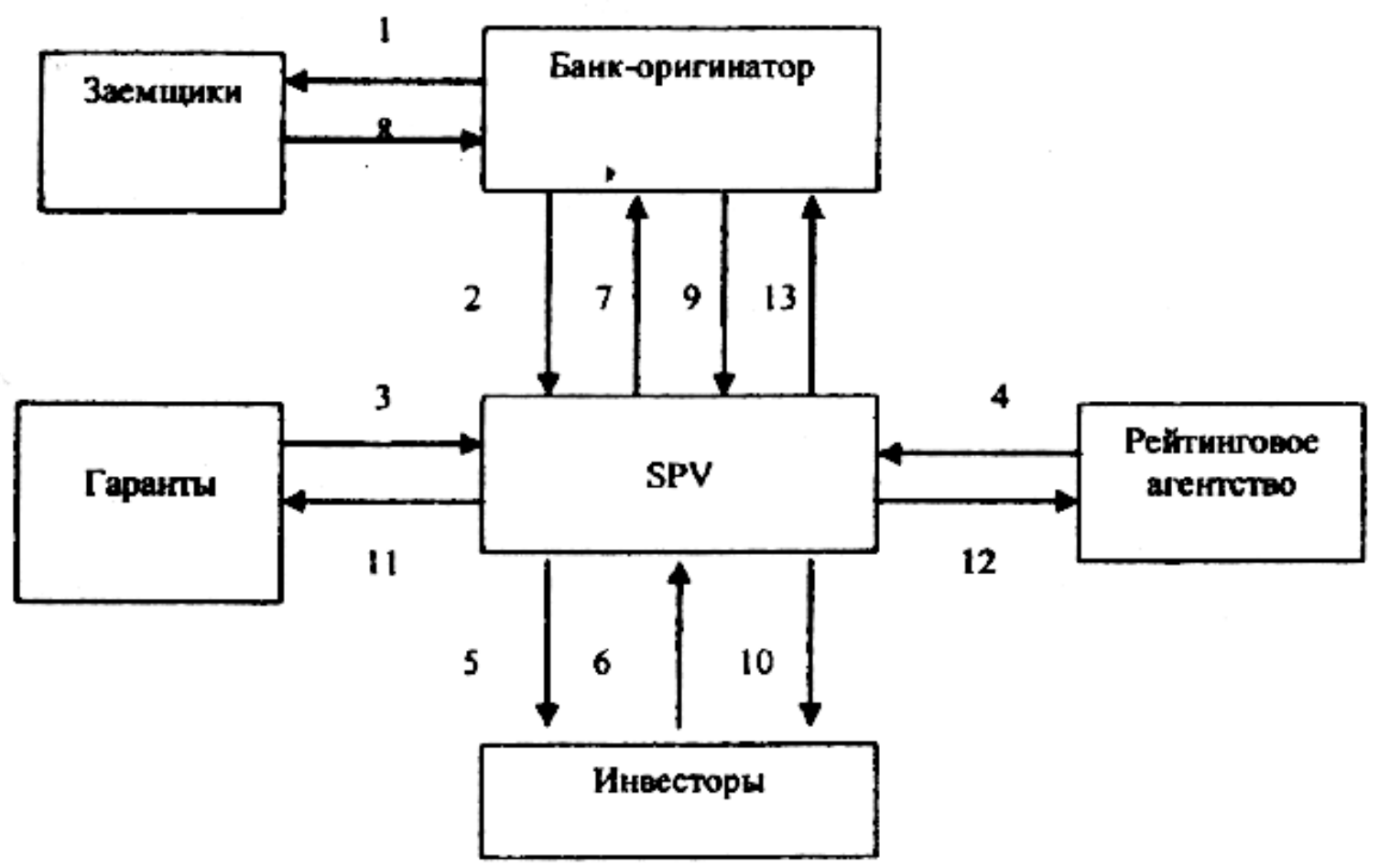

Puc. 2.2. Внебалансовая секьюритизация активов 
Таблица 1. Сравнение содержания балансовой и балансовой секьюритизации активов

\begin{tabular}{|c|c|c|}
\hline \multirow{2}{*}{ Критерии секьюритизации } & \multicolumn{2}{|c|}{ Вид секьюритизации } \\
\hline & Балансовая & Внебалансовая \\
\hline $\begin{array}{l}\text { Нахождение прав требований по } \\
\text { ипотечным кредитам }\end{array}$ & На балансе первичного кредитора & $\begin{array}{l}\text { Списываются с баланса первично- } \\
\text { го кредитора и передаются специ- } \\
\text { ализированной организации }\end{array}$ \\
\hline $\begin{array}{l}\text { Объем ответственности оригина- } \\
\text { тора }\end{array}$ & Отвечает собственным капиталом & $\begin{array}{l}\text { В рамках покрытия по кредитам и } \\
\text { дополнительного обеспечения }\end{array}$ \\
\hline $\begin{array}{l}\text { Кредитный рейтинг выпускаемых } \\
\text { бумаг }\end{array}$ & $\begin{array}{l}\text { Зависит только от рейтинга ориги- } \\
\text { натора }\end{array}$ & $\begin{array}{l}\text { Высокий рейтинг обеспечивается } \\
\text { высоким рейтингом оригинатора и } \\
\text { мерами кредитной поддержки }\end{array}$ \\
\hline $\begin{array}{l}\text { Риск досрочного погашения обяза- } \\
\text { тельств }\end{array}$ & Несет банк-эмитент & Приходится на инвестора \\
\hline Риск задержки выплат & $\begin{array}{l}\text { Может возникнуть в случае кон- } \\
\text { курсного производства в отноше- } \\
\text { нии оригинатора }\end{array}$ & Полностью исключен \\
\hline Кредитный риск & $\begin{array}{l}\text { Не передается и возлагается на } \\
\text { банк-эмитент }\end{array}$ & $\begin{array}{l}\text { Передается гарантам и/или страхо- } \\
\text { вой организации }\end{array}$ \\
\hline $\begin{array}{l}\text { Порядок погашения выпускаемых } \\
\text { ценных бумаг }\end{array}$ & $\begin{array}{l}\text { Единовременным платежом, без } \\
\text { досрочного погашения }\end{array}$ & $\begin{array}{l}\text { Выплаты в установленные сроки; } \\
\text { возможно досрочное погашение }\end{array}$ \\
\hline
\end{tabular}

тельств. Это и несовершенство законодательства (особенно в части судебной защиты срочных сделок), и неясность механизма налогообложения сделки по продаже активов SPV, а также неразвитость российского фондового рынка. К тому же необходимым для секьюритизации пулом низкорисковых стандартизированных ссуд размером в 100-150 млн. долл. обладает лишь незначительное число российских банков.

Между тем, образование в последние годы целой группы крупных институциональных инвесторов, нуждающихся в долговременных инструментах вложения средств (пенсионные фонды, паевые инвестиционные фонды, Агентство по страхованию вкладов), требует скорейшей выработки законодательного обеспечения сделок по секьюритизации активов и торговле кредитными деривативами. Первым шагом в практической деятельности по организации секьюритизации активов стало принятие Федерального закона «Об ипотечных ценных бумагах». Несмотря на то, что данный закон регламентирует только секьюритизацию ипотечных ссуд, он играет существенную роль в части применения зарубежного опыта в условиях российской экономики. Опыт первых сделок секьюритизации ипотечных активов, его анализ, позволят сформировать базу для разработки положений, регламентирующих и другие виды секьюритизации.

Таким образом, в условиях усиления турбулентности глобальной рыночной экономики задача государства сводятся к обеспечению платежеспособного спроса различных слоев населения на рынке жилья путем создания благоприятных условий для развития рыночных механизмов мобилизации внебюджетных ресурсов общества и направления их в кредитно-финансовую сферу посредством развития долгосрочного жилищного ипотечного кредитования, перехода к приобретению населением жилой недвижимости за счет собственных средств.

\section{Библиографический список}

1. Федеральный закон от (ред. от 29.06.2015) «Об ипотечных ценных бумагах» [Электронный ресурс]: федер. закон от 11.11.2003 N152-Ф3 // Консультант Плюс. - Режим доступа: http://www.consultant.ru/.

2. Проект Федерального закона «О секьюритизации» [Электронный ресурс] // Режим доступа: http://www.lin. $\mathrm{ru} /$

3. Развитие рынка ипотечного жилищного кредитования и деятельность $\mathrm{AO}$ «АИЖК» [Электронный ресурс] // Аналитический центр АО «АИЖК», Выпуск № 10, 2015 год.- Режим доступа: http://rusipoteka.ru/

4. «ВТБ 24» заложит ипотеку в ЦБ [Текст] // Ведомости. - № 3895 от 14.08.2015

5. Miquel Segoviano, Bradley jones, Petez Lindnez, and Johannes Blanrenheim, Securitization: The Road Ahead-IMF Discussion Note, January 2015

6. Securitization: The Road Ahead- IMF Staff discussion note 15/01/2015 
7. http://www. Americansecuritization.com/Recoutces/ASPX

8. http:// rusipotera/ru/files/analytics/

Поступила в редакцию 21.11.2018 